\title{
Using the Theory of Planned Behavior to Investigate What Influences Chinese Intention to Purchase Organic Food
}

\author{
Yingqi Zhu \\ The University of New York, New York, USA
}

\begin{abstract}
Organic farming is promising and the development of organic food market is imperative. So learning what influences people's intention to consume organic food is of uppermost priority. This paper incorporates self-identity and ecological motives into the theory of planned behavior (TPB) to investigate Chinese intentions to purchase organic food. A survey was conducted on 260 university students through in-depth questionnaire. The AMOS results revealed that in the modified model, only attitude and ecological motive were the independent predictors of students intention. And the subjective norm, perceived behavioral control and the added self-identity had no significant relationship with the purchasing intention.
\end{abstract}

Keywords: organic food, theory of planned behavior, self-identity, ecological motives

\section{Introduction}

Organic farming has always been considered as a promising way to solve the problems caused by traditional farming such as abuse of herbicides, declined soil fertility, water pollution led by chemicals, and so on. Contrary to the conventional farming, organic farming is characterized by controlling pests, diseases without harming the environment, increasing soil fertility and ensuring the safe quality of the water resources (Kunz \& Muller, 2009). Interest in organic food has grown remarkably as consumers and marketers react to popular media about health and environmental effects of pesticides, genetically-modified organisms, and food safety (Hughner, McDonagh, Prothero, \& Shultz, 2007). Also with the development of economy and technology, transition to the organic is absolutely the trend of the times worldwide.

Indeed due to the considerable increase of the global organic market, it has been frequently regarded as one of the biggest growth markets in food industry. In 2002, the global market for organic food was estimated to be US\$20 billion, but at the end of 2012 it reached nearly US\$64 billion. Despite the steady growth of the world market, growth was concentrated in developed countries (Li, 2002). By 2010, the Germany area for organic farming accounted for $5.93 \%$ of its total farming area and its sales of organic products was worth six million euros. In the United Kingdom, the organic sales reportedly increased from £100 million in 1994 to £605 million in 2000. And by 2010, its area for organic farming accounted for $4.34 \%$ of its total farming area, and its sales of organic products reached two billion euros. Similar to United States and Japan, UK also experienced the growth in both organic farming area and sales in the past few decades (Wang \& Li, 2015). As one of the

Yingqi Zhu, graduate student, School of Professional Studies, The University of New York, New York, USA.

Correspondence concerning this article should be addressed to Yingqi Zhu, School of Professional Studies, The University of New York, New York 10012, USA. 
largest developing countries in the world, China did not start organic farming until the 1980s. It was at 2003 that the government established certification system for organic products (Huang, 2013). Though the organic industry in China has developed rapidly in the past few decades, in 2012 the export of Chinese organic products was only \$400 million (Zhang et al., 2012).

Obviously, there is a gap between the organic industry in China and that in other developed countries. Not only does the legislative regulation which includes the agriculture production system and the certification system influence the growth of organic industry, but also the market level factor which includes the buyers and sellers determines the final performance of organic industry.

Given the fact that the Chinese government is now increasing the policy support to accelerate the pace of organic industry and the high premium of organic products drivers more growers to organic industry, it is the consumers who become the most pivotal part of the organic industry. Due to the fact that the marketing strategies are based on the consumer willingness to pay higher prices, consumer beliefs, and consumer attitudes towards organically grown products (Aryal, Chaudhary, Pandit, \& Sharma, 2009), so a study of what influences Chinese consumers to purchase organic products seems imperative. Results from this study can help formulate organic market strategies and implement related programs. However, compared to research in the United States and Europe, very little research has been conducted in mainland China. So this article aims to provide empirical data on Chinese consumers' intention to buy organic products and to examine what drives those intentions.

As the descendants of a large agricultural nation, Chinese learned the core of organic agriculture thousands of years ago (Cheng \& Zhang, 2007). But with the wide spread of chemical agriculture in the 20th century, people relied more on the chemical fertilizers and pesticides to pursue excessive output and overlooked the quality of crops. Nowadays China's agriculture faces such problems as low productivity and rough management which resulted from the wide acceptance of chemical agriculture. Additionally, due to the deterioration of environment, limited per capita resources becomes more apparent (Li, Wang, \& Guo, 2013). Those mentioned above explain partly why developing organic industry seems so urgently. And because the term "organic" has only come to be known by Chinese for less than 30 years, the main barrier to boom the industry is the lack of consumers' awareness and intention to buy organic products.

The population of this research is selected specifically among the undergraduate and graduate students. Compared to the general population, this well-educated group has the basic understanding of the organic industry and of the negative effects caused by chemical farming, which provides them more chance to do organic purchase. Unlike their last generation, young people are more readily to change (Lenzen \& Murray, 2001). Exposed to mass information every day, people still keep exploring new things day and night, so the open-minded ones are more likely to adopt to the current world and wield it. Additionally, according to a study conducted (Vermeir \&Verbeke, 2008), young people will become the mainstream consumers in the future. Given that they will dominate the world in the next few decades, knowing young people's thoughts and preferences contributes a lot to grasp chances and win initiatives among competitors. Also, as the adults, they already have the ability to influence the food purchase in their own households (Yazdanpanah \& Forouzani, 2015).

\section{Theoretical Framework}

The theory of planned behavior (TPB) is a expectancy-value model of attitude-behavior relationships (Conner \& Armitage, 1998), which has been widely accepted by most social psychologists to understand and 
predict human behavior. And a general rule is that the stronger the intention to engage in behavior, the more likely should be its performance. By using this model, people's behavior can be predicted through three components: attitudes, subjective norms, and perceived behavioral control (PBC). Attitudes refer to the degree to which performance of the behavior is positively or negatively valued. Subjective norms refer to the social pressure you receive from people around you and people that are important to you in your life. And PBC refers to whether it is easy or difficult to perform the particular behavior.

TPB has always been utilized in the area of food choice especially in the organic food choice recently (Aertsens, 2009). Even though the theory of planned behavior has been applied successfully as a framework to understand consumer decision on organic foods, to identify factors that determine people's behavior in environmental activism (Fielding, Mcdonald, \& Louis, 2008), and to help many researches in other areas, there are many scientists in various research fields arguing that other variables should be added to increase the predictive utility of the model. In fact, the TPB has recently been criticized for its overlook to other constructs (Yazdanpanah \& Forouzani, 2015). To make up this flaw, this study has added self-identity and ecological motives in the original TPB model.

The connection between self-identity and behavior was first proposed in identity theory (Stryker, 1968). Even though identity theory and TPB seem very compatible in regarding behavior, they have totally different focuses; one focuses in the wider social characteristic whereas the other pays more attention to the constrained normative components (Charng, Piliavin, \& Callero, 1988). Now there is an increasing amount of research that has been done to support that self-identity as an essential predictive construct of people's behavior. In the study (Mark \& Christopher, 1998) which was supported by numerous empirical and theoretical evidence, self-identity was reasonably assumed as a useful addition to the TPB. Self-identity has been proven an effective predictor when it is incorporated into the TPB in the study of intention to engage in environmental activism (Fielding et al., 2008). In the research which uses the extended model of TPB making self-identity an additional variable to predict social networking web sites (SNWs) use intentions, self-identity has been found significantly contributed to the prediction of intention (Pelling \& White, 2009). In terms of food choice, the effectiveness of modification of TPB including self-identity has been proven. It has been found that self-identity was significant in determining intention to purchase GM food (Cook, Kerr, \& Moore, 2002), especially in a study (Sparks \& Shepherd, 1992), which found that self-identity can influence the intentions to buy organically grown vegetables independently. Therefore, adding self-identity into the original TPB model can increase the explanatory power of the model.

Inclusion of an ecological motive in TPB has not been done in many studies, but there is an increasing number of related studies which show that ecological motive can significantly influence people's intention in organic food purchase (Teng \& Lu, 2016). Ecological motives consist of environmental concerns and animal right issues. According to the study (Hemmerling, Hamm, \& Spiller, 2015), environmental protection was one of the most important product attributes that influence the motive to purchase organic food. In the review (Yiridoe, Bonti-Ankomah, \& Martin, 2005), environmental effects and farm animal welfare aspects are the characteristics that are important to consumers when they choose organic food rather than conventionally grown products. The importance of environmental and animal rights issues to organic food consumers has been demonstrated by the study which aims to investigate the role of ethical motives in organic food choice (Honkanen, Verplanken, \& Olsen, 2006). Organic food consumers are always with higher environmental consciousness than non-organic consumers for that is one reason why they choose to purchase organic food. 
And when compared to those who show less environmental concerns, the organic food buyer often stick to environmental principles which has already been reflected on their purchase. So in this paper, the writer separates the ecological motive from the abstract moral or ethical values that are preferred by many other scientists. Given that the intrinsic attribute the organic food possesses and the unique characteristic the organic food consumers have, the additional of ecological motive in the TPB model can evaluate the intention of consumers more pertinently. In total, based on the TPB model, the study has proposed those hypotheses:

(1) Attitude will positively affect behavioral intention.

(2) Subjective norm will positively affect behavioral intention.

(3) Perceived behavioral control will positively affect behavioral intention.

(4) Self-identity will positively affect behavioral intention.

(5) Ecological motive will positively affect behavioral intention.

\section{Methodology}

\section{Participants}

The study conducted an in-depth survey on the students from several different universities located in Hubei Province. The total involvement of the investigated students was 260 and they were all chosen through random sampling. The survey was implemented online during June 2016 and 260 questionnaires were sent out whereas the valid 216 feedback were received. All the people questioned were fully informed that the information they provided would stay anonymous and confidential. All the students invited could refuse to participate and for those who chose to take part in this survey, they also had the freedom to avoid the question they assumed sensitive or felt difficult to answer. None of the respondents was obliged to finish the questionnaire completely. Most of the responses were submitted through mobile phone and computer. In addition, no pecuniary award was provided for students who answered the question. The data-integrity was guaranteed by computer filter and the validity of the data was supported by the specially designed selection question.

\section{Data Collection Techniques}

The questionnaire was designed through reading lots of related literature and referring to the questionnaires which had already been conducted successfully. The variables contained in this questionnaire was guided by the modified model of the theory of planned behavior mentioned above including attitudes, subjective norms, perceived behavioral control, self-identity, and ecological motives with regard to consuming organic food. The extend to each question the respondents agreed or disagreed was measured by the five-point scale (one represented very disagreed and five represented very agreed).

Table 1 shows the variables and their corresponding coefficients in the questionnaire. Because this questionnaire was referred to questionnaires examined by a panel of experts from related disciplines, its validity was undisputed. Also according to Table 1, the Cronbach alpha coefficients for most scales suggested a good level reliability ranging from 0.66 to 0.91 . The result of low alpha coefficient for PBC is just consistent with the results of Fielding et al. (2008) and Yazdanpanah and Forouzani (2015). The alpha coefficient for PBC in this case which reached 0.66 may not be adequate as usually considered, but when compared with the alpha coefficient for PBC in case of Yazdanpanah and Forouzani which was 0.627, the performance of this study is great. 
Table 1

Constructs/Variables and Their Coefficients in the Questionnaire

\begin{tabular}{lll}
\hline Construct/Variable & A Cronbach coefficient & Number of statements \\
\hline Intention & 0.915 & 3 \\
Attitude & 0.886 & 5 \\
Subjective norm & 0.866 & 4 \\
Perceived behavioral control & 0.666 & 3 \\
Self-identity & 0.780 & 2 \\
Ecological motives & 0.918 & 4 \\
\hline
\end{tabular}

\section{Results}

\section{Descriptive Statistics}

In terms of demographic characteristics of the respondents, 100 of them were male accounting for $38.46 \%$ of the invited people whereas the number of female was 160 which accounted for $61.54 \%$. Regarding the household average income per person, 8.46\% of the respondents earned less than 2000 yuan, and people who made 2,000 to 3,000 monthly owned the largest proportion which was $20.77 \%$. And the ration of respondents whose monthly pay was between 3,001 and 4,000 yuan was $19.62 \%$ ranking second. The portion of monthly earn between 4,001 to 5,000 yuan was $15.77 \%$ which was moderate. And the proportion of income from 5,001 to 6,000 yuan and income from 6,000 to 7,000 yuan were $8.85 \%$ and $6.92 \%$ separately. And for people who made money more than 7,000 yuan per month, their number was relatively high and made up of $19.6 \%$ of the whole respondents. With the regard to organic food purchase behavior, there were $81.15 \%$ of the total respondents claiming that they had bought organic food before, which was an extremely high ratio. And according to the filter question, only 216 questionnaires received were valid.

\section{Modified Model: Description \& Variables}

Table 2

Descriptive Analysis of Variables

\begin{tabular}{lll}
\hline Variables & Mean & SD \\
\hline Intention & 3.84 & 0.69 \\
Attitude & 3.58 & 0.62 \\
Subjective norm & 3.23 & 0.72 \\
Perceived behavioral control & 3.53 & 0.63 \\
Self-identity & 3.00 & 0.73 \\
Ecological motives & 4.17 & 0.75 \\
\hline
\end{tabular}

From Table 2, the average values of all variables are pretty close. The added variables show extreme mean values: The ecological motives have the highest mean whereas the mean of self-identity was the lowest. Also the average of subjective norm was the second lowest among the five variables. Those data share the similar features of the results of the study conducted by Yazdanpanah and Forouzani which show low mean values of subjective norms and self-identity. This can be explained by the current situation of both countries. Because as developing countries, the domestic organic industries start late and also the idea of consuming organic food is not universal among the population. The results show that our sample people have intense environmental obligation to consumer organic food and their positive attitudes towards buying organically grown food are relatively high. Furthermore, the samples show high confidence that they can purchase organic food under their control easily. 
Table 3

The Pearson Correlation Test Between All Variables

\begin{tabular}{|c|c|c|c|c|c|c|}
\hline Variables & Intention & Attitude & $\begin{array}{l}\text { Subjective } \\
\text { norm }\end{array}$ & $\begin{array}{l}\text { Perceived } \\
\text { behavioral control }\end{array}$ & Self-identity & $\begin{array}{l}\text { Ecological } \\
\text { motives }\end{array}$ \\
\hline Intention & 1 & & & & & \\
\hline Attitude & $0.596^{* *}$ & 1 & & & & \\
\hline Subjective norm & $0.456^{* *}$ & $0.532^{* *}$ & 1 & & & \\
\hline Perceived behavioral control & $0.478^{* *}$ & $0.406^{* *}$ & $0.529 * *$ & 1 & & \\
\hline Self-identity & $0.352^{* *}$ & $0.665^{* *}$ & $0.507^{* *}$ & $0.454^{* *}$ & 1 & \\
\hline Ecological motives & $0.638^{* *}$ & $0.275^{* *}$ & $0.200^{* *}$ & $0.427^{* *}$ & $0.141^{*}$ & 1 \\
\hline
\end{tabular}

Notes. $* *$ means $p<0.01$ and $*$ means $p<0.05$.

In order to figure out the relationship between variables, Pearson correlation test was conducted, and the results were presented in Table 3. The results revealed that the intention to purchase organic food had a strong relationship to attitudes and ecological motives. Both the relationship between intention and perceived behavior control and the relationship between intention and subjective norms were moderate, though the former was greater. And the relationship between the intention to buy organic food and self-identity was weak.

Table 4

Comparison of Attitude, Ecological Motives and Intention Regarding Organic Food Across Groups

\begin{tabular}{|c|c|c|c|c|c|c|}
\hline \multirow{2}{*}{ Variables } & \multicolumn{2}{|c|}{ Male } & \multicolumn{2}{|c|}{ Female } & \multirow{2}{*}{ - T. value } & \multirow{2}{*}{ Sig. } \\
\hline & Mean & SD & Mean & SD & & \\
\hline Attitude & 3.43 & 0.63 & 3.67 & 0.60 & -2.705 & 0.008 \\
\hline Ecological mtives & 3.94 & 0.88 & 4.31 & 0.62 & -3.700 & 0.000274 \\
\hline Intention & 3.56 & 0.76 & 4.01 & 0.59 & -4.928 & 0.000002 \\
\hline
\end{tabular}

T-test was conducted to find out the differences and similarities in terms of attitudes, ecological motives and intention to buy organic food when categorized by gender. The results from Table 4 turned out that female had higher mean values of all three variables than males. According to the standard deviations, it could be assumed that females' opinions were more concordant than males'. To conclude, the differences did exist between males and females in aspect of attitude, ecological motives and intention to purchase organic food.

\section{The Modified Model}

In this study, the writer used AMOS software to build up a structural equation modeling (SEM) to testify the proposed hypotheses. And the measurement model called CFA was applied to assess the validity of the constructs. The validation of the model depended on the extent to which the empirical data were fitted and whether the indicative index met the specific standards. Here are some common requirements accepted widely: Chi-square normalized by degrees of freedom is excellent when it is less than two and it is good when it is less than three; goodness-of-fit (GFI) should be larger than 0.9; the adjusted goodness-of-fit index (AGFI) should be larger than 0.8 (Henry \& Stone, 1994); normal fit index (NFI) and comparative fit index (CFI) can be considered excellent when they reach 0.95 , but 0.9 is enough to attain normal level; as for root mean square error (RMSE), it should be less than 0.08 at least and it can reach excellence when it is less than 0.05 (Minglong, 2012).

The results of the model's overall fit measurements are shown in Table 5. Given the standards mentioned above, all the index suggested that this modified TPB model fitted pretty good through an empirical test and should be accepted. 
Table 5

Models' Evaluation Overall Fit Measurements

\begin{tabular}{lllllll}
\hline Models & $\chi^{2} / \mathrm{df}$ & GFI & AGFI & NFI & CFI & RMSE \\
\hline MTPB & $122.742 / 51=2.41$ & 0.915 & 0.870 & 0.940 & 0.964 & 0.038 \\
\hline
\end{tabular}

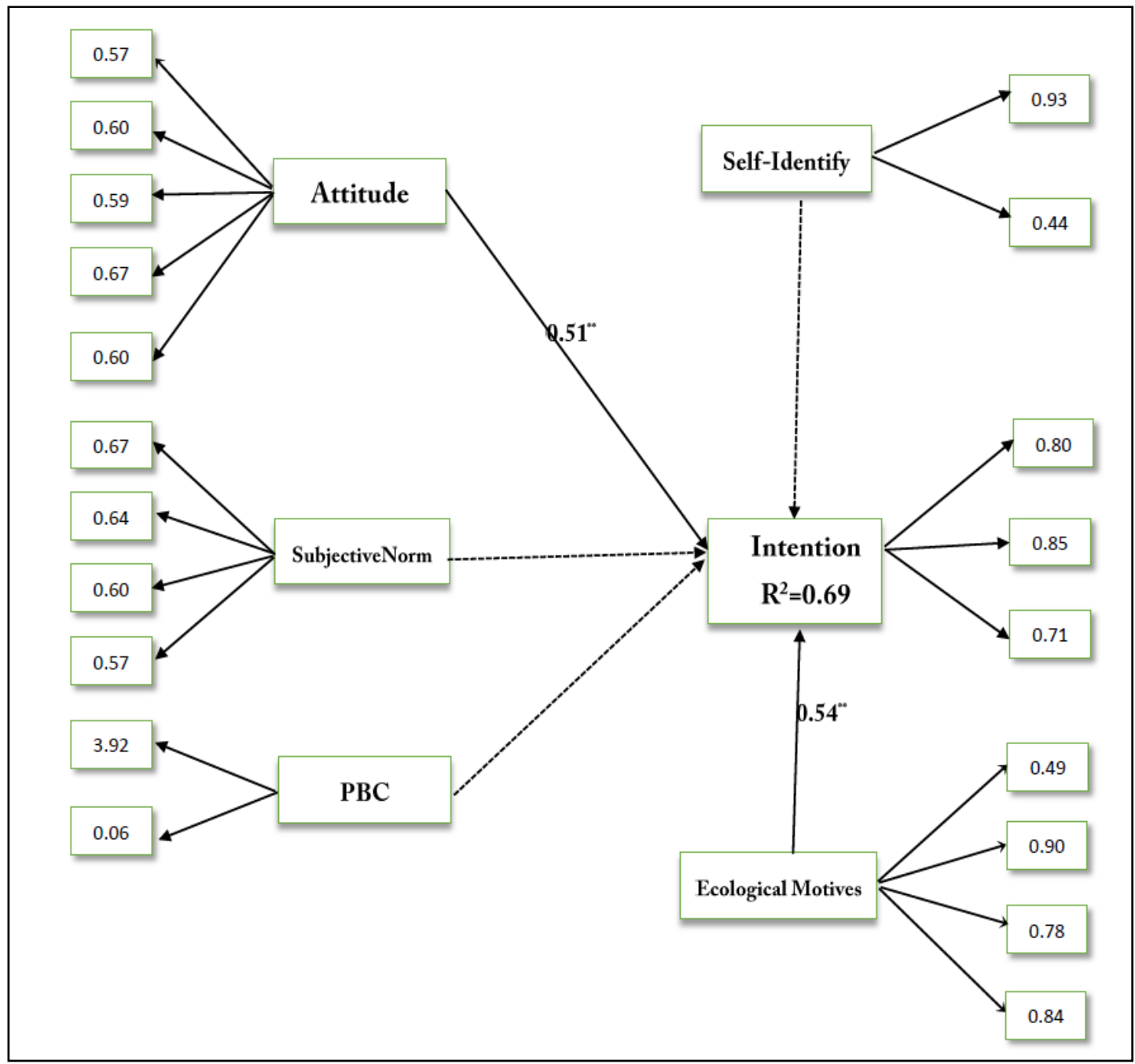

Figure 1. Modified model based on the theory of planned behavior.

The modified TPB model explained $69 \%$ of constructs in intention to consumer organic food. In this modified model, only the attitude and the ecological motives were considered as the predictor of the intention. The attitude had a strong positive relationship with the intention, which was consistent with the results of many other studies that had applied TPB model to explore consuming organically grown food. But in this study, the relationship between subjective norms was very weak. In earlier researches regarding organic food purchase with the adoption of TPB model, the relationship between subjective norms and intention was not identical. Many had found there was s significant relationship (Vermeir \& Verbeke, 2008; Chen, 2007; Dean, Raats, \& Shepherd, 2008) whereas some other scholars agreed that the relationship was not significant (Yazdanpanah \& Forouzani, 2015). Though the addition of self-identity was assumed to increase the explanatory power, it turned out this case did effect. And this result was interesting, because in the research conducted by Yazdanpanah and 
Forouzani, self-identity was the predictor of intention to purchase organic food. But the results revealed that the ecological motives did have a positive influence on people's intention. The results of hypotheses are presented as follows:

(1) Attitude will positively affect behavioral intention.

(2) Subjective norm will not positively affect behavioral intention.

(3) Perceived behavioral control will not positively affect behavioral intention.

(4) Self-identity will not positively affect behavioral intention.

(5) Ecological motive will positively affect behavioral intention.

\section{Discussion}

This paper provided a specifically-designed social psychological model to examine Chinese consumers' intentions to purchase organic food. With the aim to improve the explanatory power of the TPB model, combined with the current research results which revealed the variable influence people's intention, this modified model incorporated measures of self-identity and ecological motives. As the result, this upgraded model had managed to account for organic food purchase intention, which predicted $69 \%$ variance in total. However, the SEM revealed that only the attitude and the ecological motive in the revised model were the predictors of intention while subjective norms, perceived behavior control, and self-identity were not significant predictors.

The subjective norm construct is always considered to be a weak predictor of intentions (Christian, Armitage, \& Abrams, 2003). In current study regarding organic food purchase, the relationship between subjective norms and intention has been proved insignificant in several researches (Yazdanpanah \& Forouzani 2015). There is also a paper which concluded no direct significance between subjective norm and organic food buying (Tarkiainen \& Sundqvist, 2005), which in turn reinforce the validity of the results of this study. As for perceived behavior control, its relationship with intention to purchase organically grown food has been examined many times and the results turn to be insignificant most of the time. In the study which investigated the intention to purchase organic food in Iran, the relationship between PBC and intention was insignificant. Similar in the study (Dean et al., 2008), its path was not significant either. There are also other studies with the results of significant relationship, but the organic food they chose to investigate seems to be more specific and when people are informed to purchase a single product, they surely will feel easier to control over. So it is reasonable that they will feel difficult to make up their own minds when they are exposed to an abstract concept with no detailed information to support.

According to the review which regarded extending the theory of planned behavior (Conner \& Armitage, 1998), the relationship between self-identity and intention varied from insignificant to significant, so the strength of this correlation was not identical. But in current study, self-identity has more emerged as an independent predictor of intention in many research fields such as environmental activism and organic food purchase. But this paper found out that self-identity was not an independent predictor which was inconsistent with the former studies. But this can be explained by the current national condition of China. The initial assumption is that the stronger the sense of being an organic food consumer, the greater the people's intention to purchase. But for Chinese people who just encounter the conception of organic food, it is impossible to force them to convert the abstract word into a lifestyle immediately. The lack of necessary information leads to people's insufficient recognition of organic food. And when the consumers fail to understand it and connect it to their day-to-day life, cultivation of such identity is sheer fantasy. 
Even though many studies chose to make moral norm the additional construct of the TPB model, this paper chooses to add ecological motive instead. Moral norm seems more abstract and contains too much subtle variables. This study aims to separate the ecological motive which has been classified as part of the moral norm and accounted much in people's moral code. Just as moral norm has been proven as a significant independent predictor on intention in many researches, this paper also showed ecological motive the independent predictor regarding buying organic food. The findings suggest that the more an individual shows it is an ecological obligation to buy organic food, the greater his/her intention is. Also, the results indicate that the ecological motive may account most for people's moral norm when regarding organic food purchase.

This study provides a specially-designed TPB model to investigate people's intention to purchase organic food. Attitude is the detrimental variable that influences people's intention to buy and ecological motive also has a significant relationship with purchasing intention. So for organic food marketers who want to increase the sales in the future, figuring out what influence people's attitude towards organic food is the top priority. Given that people buy organic food always out of ecological concerns, attaching environmental value and animal welfare to the product will definitely enhance people's awareness to purchase. Even though self-identity has not been proven as a capable predictor, but as time changes and organic market develops, the variables that influence people’s intention may vary too.

\section{Conclusion}

This paper proposed a modified TPB model to investigate the variables influencing people's intention to purchase organic food. The additions of self-identity and ecological motive were aimed to increase the explanatory power of the model, but the self-identity turned to be ineffective. The results revealed that attitude and ecological motive had significant relationship with intention, which indicated how to increase people's intention to buy organic food in future. However, there were some limitations of the paper. First, the number of people who involved in the research was not relatively large, so there is still a lift in the sample quality. Second, the modified model is time-based. It just aimed at figuring out what are the most important variables currently, so it may not function well in the future when Chinese organic market develops.

\section{References}

Aryal, K. P., Chaudhary, P., Pandit, S., \& Sharma, G. (2009). Consumers’ willingness to pay for organic products: A case from Kathmandu Valley. Journal of Food Agriculture \& Environment, 10(6), 15-26.

Aertsens, J. (2009). Personal determinants of organic food consumption: A review. British Food Journal, 111(10), 1140-1167.

Charng, H. W., Piliavin, J. A., \& Callero, P. L. (1988). Role identity and reasoned action in the prediction of repeated behavior. Social Psychology Quarterly, 51, 303-317.

Cheng, Y., \& Zhang, C. (2007). Study on production technology of organic agriculture. Journal of Modern Agricultural Sciences and Technology, 16, 69-69.

Christian, J., Armitage, C. J., \& Abrams, D. (2003). Predicting uptake of housing services: The role of self-categorization in the theory of planned behaviour. Current Psychology, 22(3), 206-217.

Conner, M., \& Armitage, C. J. (1998). Extending the theory of planned behavior: A review and avenues for further research. Journal of Applied Social Psychology, 28(15), 1429-1464.

Cook, A. J., Kerr, G. N., \& Moore, K. (2002). Attitudes and intentions towards purchasing GM food. Journal of Economic Psychology, 23(5), 557-572.

Dean, M., Raats, M. M., \& Shepherd, R. (2008). Moral concerns and consumer choice of fresh and processed organic foods. Journal of Applied Social Psychology, 38(8), 2088-2107. 
Fielding, K. S., Mcdonald, R., \& Louis, W. R. (2008). Theory of planned behaviour, identity and intentions to engage in environmental activism. Journal of Environmental Psychology, 28(4), 318-326.

Huang, H. (2013). Study on the development of organic agriculture and its industrialization in China. Chengdu, China: Southwestern University of Finance and Economics.

Hemmerling, S., Hamm, U., \& Spiller, A. (2015). Consumption behaviour regarding organic food from a marketing perspective-A literature review. Organic Agriculture, 5(4), 277-313.

Honkanen, P., Verplanken, B., \& Olsen, S. O. (2006). Ethical values and motives driving organic food choice. Journal of Consumer Behaviour, 5(5), 420-430.

Henry, J. W., \& Stone, R. W. (1994). A structural equation model of end-user satisfaction with a computer-based medical information system. Information Resources Management Journal, 7(3), 21-33.

Hughner, R. S., McDonagh, P., Prothero, A., Shultz, C., \& Stanton, J. (2007). Who are organic food consumers? A compilation and review of why people purchase organic food. Journal of Consumer Behaviour, 6(2-3), 94-110.

Kunz, L., \& Muller, A. (2010). A case-study on project-level $\mathrm{CO}_{2}$ mitigation costs in industrialised countries-The climate cent foundation in Switzerland. Journal of Environmental Planning and Management, 53(5), 657-676.

Lenzen, M., \& Murray, J. (2001). The role of equity and lifestyles in education about climate change: Experiences from a large-scale teacher development program. Canadian Journal of Environmental Education, 6, 32-51.

Li, Y., Wang, Y., \& Guo, H. (2013). Research on the evolution and regional comparison of organic agriculture at home and abroad. Journal of World Regional Studies, 3, 110-117.

Li, Z. (2002). Development of organic agriculture in the world. Journal of Agricultural Environment and Development, 19(1), 43-44.

Pelling, E. L., \& White, K. M. (2009). The theory of planned behavior applied to young people's use of social networking web sites. Cyberpsychology \& Behavior the Impact of the Internet Multimedia \& Virtual Reality on Behavior \& Society, 12(6), 755.

Stryker, S. (1968). Identity, salience and role performance: The relevance of symbolic interaction theory for family research. Journal of Marriage and the Family, 30, 558-564.

Sparks, P., \& Shepherd, R. (1992). Self-identity and the theory of planned behaviour: Assessing the role of identification with “green consumerism”. Social Psychology Quarterly, 55(4), 388-399.

Teng, C. C., \& Lu, C. H. (2016). Organic food consumption in Taiwan: Motives, involvement, and purchase intention under the moderating role of uncertainty. Appetite, 105, 95-105.

Tarkiainen, A., \& Sundqvist, S. (2005). Subjective norms, attitudes and intentions of Finnish consumers in buying organic food. British Food Journal, 107(11), 808-822.

Vermeir, I., \& Verbeke, W. (2008). Sustainable food consumption among young adults in Belgium: Theory of planned behaviour and the role of confidence and values. Ecological Economics, 64(3), 542-553.

Wang, H., \& Li, X. (2015). Research on the development trend of organic agriculture in the world and its enlightenment to China. Journal of Statistics and Management, 1, 91-93.

Wu, M. (2012). Advanced-AMOS structural equation model practice. Chongqing, China: Chongqing University.

Yiridoe, E. K., Bonti-Ankomah, S., \& Martin, R. C. (2005). Comparison of consumer perceptions and preference toward organic versus conventionally produced foods: A review and update of the literature. Renewable Agriculture \& Food Systems, 20(4), 193-205.

Yazdanpanah, M., \& Forouzani, M. (2015). Application of the theory of planned behaviour to predict Iranian student' intention to purchase organic food. Journal of Cleaner Production, 107, 342-352.

Zhang, J., Hu, Y., Xie, W., \& Wang, X. (2012). Discussion on the development of organic products in China under the new situation. Journal of Management of Agriculture Science and Technology, 31(6), 1-3. 